\title{
Synthesis and characterization of niobium-doped fish scale-derived hydroxyapatite by physical ultrasound interference
}

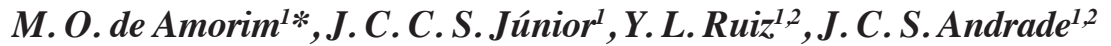 \\ ${ }^{I}$ Federal University of Amazonas, Faculty of Technology, Department of Materials Engineering, \\ Laboratory of Processing Technological Materials, Av. Gen. Rodrigo Otávio 6200, Manaus, AM, Brazil \\ ${ }^{2}$ Federal University of Amazonas, Post-Graduate Program in Science and Materials Engineering, \\ Manaus, AM, Brazil
}

\begin{abstract}
Fish scales of the Arapaima gigas (pirarucu) species were heat-treated to obtain natural hydroxyapatite (HAp), and it was doped with niobium $(\mathrm{Nb})$ by physical ultrasound interference to confirm an effective route to the production of Nb-doped HAp powders. The effect of ultrasound application on doping was investigated. The structure of the powders was elucidated using X-ray diffractometry (XRD), scanning electron microscopy, IR spectroscopy, and X-ray fluorescence spectroscopy (XRF). XRD results of Nb-doped HAp powders were compared with undoped natural hydroxyapatite and ICSD-26204 standard as controls. The crystallinity of Nb-doped HAp powders increased from $39 \%$ to $51 \%$ after the ultrasound application. IR spectroscopy confirmed hydroxyl, carbonate, and phosphate functional groups in the sample. Results obtained by XRF confirmed the ionic substitution of Ca for Nb with an average content of $1 \%$. Therefore, the effectiveness of the synthesis route was confirmed to produce hydroxyapatite-niobium crystalline powder with physicochemical integrity as a potential biomaterial for bone implant application.
\end{abstract}

Keywords: natural hydroxyapatite, niobium, powders, ultrasound.

\section{INTRODUCTION}

Hydroxyapatite $\left[\mathrm{Ca}_{10}\left(\mathrm{PO}_{4}\right)_{6}(\mathrm{OH})_{2}\right]$ is considered a healing material because its interaction with surrounding tissue provides a conductive microenvironment that enables the bone formation and growth [1]. There is a superficial chemical similarity between hydroxyapatite (HAp) and bone, which permits a better cell interaction with the HAp once implanted in the host $[2,3]$. The HAp presents molar ratio $\mathrm{Ca} / \mathrm{P}$ equal to 1.67 [4], and its hexagonal unit cell has $\mathrm{a}=\mathrm{b}=9.389 \AA, \mathrm{c}=6.869 \AA, \alpha=\beta=90^{\circ}$, and $\gamma=120^{\circ}[5]$. In recent years, there are a large number of studies involving the synthesis of natural hydroxyapatite from biogenic sources through heat treatment [6-9]. Besides, methods to obtain the hydroxyapatite powders can be combined with the physical interference methods. Brundavanam et al. [10] proved the application of physical effects to stimulate chemical reactivity in mixtures. The recommended equipment for this procedure is an ultrasonic homogenizer because it is more efficient due to the high cavitation energy [10].

The doping of a ceramic structure with metallic elements through combined synthesis routes would result in a promising product in the development of biomaterials. In this case, niobium is an example of a metal element with excellent mechanical properties, biocompatibility, and corrosion resistance $[11,12]$. The niobium oxide presents low cytotoxicity, bioactivity, and biocompatibility in a

*mateusoliveiradeamorim@gmail.com

Dhttps://orcid.org/0000-0002-6254-2222 ceramic structure $[13,14]$. Besides, niobium ions are obtained in the laboratory when the chemical species $\mathrm{Nb}(\mathrm{V})$ is introduced into an aqueous solution. The aqueous solution must be under constant agitation for ion exchange between the niobium and calcium ions. On the other hand, niobium ions can replace phosphorus ions in the ceramic structure (HAp), and they form the O-P-O-Nb-O bonds [15].

This study investigated the effects of adding niobium ions in a matrix of HAp obtained from fish scales of the Arapaima gigas species after the physical ultrasound interference application. The samples were investigated by structural, chemical, and morphological characterization tools to confirm the presence of hydroxyapatite-niobium crystalline powder with physicochemical integrity.

\section{MATERIALS AND METHODS}

Obtaining natural hydroxyapatite: the scales of Arapaima gigas (pirarucu) were purchased from Iranduba Frigorífico Pescados located in Iranduba, Brazil. The scales were separated and washed under running water at room temperature. Thereafter, the synthesis method comprised the heat treatment route at $700{ }^{\circ} \mathrm{C}$ for $2 \mathrm{~h}$ at a heating rate of $10{ }^{\circ} \mathrm{C} / \mathrm{min}$. This procedure comprised the removal of organic parts and the formation of HAp crystals induced by thermal energy [6-9]; then, the heat-treated material was cooled in a closed container. After that, the sample was sieved (325 mesh) to obtain a uniformly homogenized powder, and the sample was stored in Eppendorf tubes for the physical, chemical, and morphological characterizations. 
Doping with niobium ions: the niobium chloride solution was prepared by the addition of $0.27 \mathrm{~g}$ of niobium chloride (Sigma, 99\%) and $100 \mathrm{~mL}$ of ethanol, both placed in a container, and the mixture was stirred vigorously for $10 \mathrm{~min}$. A quantity of niobium chloride to substitute $1 \mathrm{wt} \%$ Ca with $\mathrm{Nb}$ was added to the solution. The HAp powder obtained in the previous step was added to the niobium chloride solution. The synthesis was performed by mixing, always under stirring by a magnetic stirrer to provide the availability of $\mathrm{Ca}^{2+}$ and $\mathrm{PO}_{4}^{3-}$ ions for the $\mathrm{Nb}$ ion replacement reaction. After that, the precursor solution was filtered. The sample was washed 3 times with deionized water $(30 \mathrm{~mL})$ to remove the unreacted ions. Finally, the material was dried in an electric oven at $110{ }^{\circ} \mathrm{C}$ for $24 \mathrm{~h}$. Thereafter, heat treatment was performed at $900{ }^{\circ} \mathrm{C}$ in a muffle furnace for $3 \mathrm{~h}$ at a heating rate of $10{ }^{\circ} \mathrm{C} / \mathrm{min}$. The procedure was completed with a sieving step (325 mesh).

Physical ultrasound interference: a QR1000 Ultrasonic Sonicator (Eco-Sonics) was used to cause physical agitation at a frequency of $20 \mathrm{kHz}$ for $30 \mathrm{~min}$ and $70 \%$ ultrasonic power control. After physical ultrasound interference, the sample was placed for maturation for $24 \mathrm{~h}$; then, it was washed 3 times with deionized water and dried in an electric oven for $24 \mathrm{~h}$ at $100{ }^{\circ} \mathrm{C}$.

Characterization techniques: the samples were analyzed by X-ray diffraction (XRD) using Panalytical Empyrean $\mathrm{X}$-ray diffractometer with $\mathrm{CuK} \alpha$ radiation $(1.5418 \AA)$ in a range of $10^{\circ}$ to $100^{\circ}(2 \theta)$. Fourier-transform infrared (FTIR) spectroscopy was performed with IRAffinity-1 Shimadzu spectrometer with 32 scans in the range of 4000 to $400 \mathrm{~cm}^{-1}$. Each sample was mixed with $\mathrm{KBr}$ at a ratio of 1:100 and vacuum-pressed. The $\mathrm{X}$-ray fluorescence (XRF) spectroscopy was performed on powders by Panalytical Epsilon 3-X equipment with a voltage of $50 \mathrm{kV}$ and a maximum current of $3 \mathrm{~mA}$ in a helium gas atmosphere (10 atm). The crystallite size was determined using the Scherrer equation, and the crystallinity was determined using the Rietveld refinement with the GSAS Crystallography Data and High Score Plus programs.

\section{RESULTS AND DISCUSSION}

Table I shows the phases obtained after the refinement of XRD data. The presence of niobium oxide in the HAp matrix allows a potential application in implants and bone restoration. Wei et al. [16] developed HAp nanocomposites with niobium that showed improvements in biological and mechanical properties, and this could make the material composed of bioactive HAp-Nb and allows better cell interaction with bone tissue. The monolithic apatite structure is present in the XRD patterns in Fig. 1. The structural integrity was maintained, as shown by the peaks in the range of $20^{\circ}$ to $35^{\circ}$. This range includes the reflection by crystalline planes with Miller indices of (200), (111), (002), (102), (210), and (300) [7, 14, 17-19]. Furthermore, a well-defined structure and peaks are shown. There were secondary phases with low-intensity peaks due to calcium and phosphorus byproducts [20]. The crystallinity of the precipitates was high due to heat treatment. The peaks of the $\mathrm{HAp}-\mathrm{Nb}$ curve were composed of the phases $\mathrm{HAp}, \mathrm{CaNb}_{2} \mathrm{O}_{6}$, and $\mathrm{Nb}_{2} \mathrm{O}_{5}$, due to the replacement of calcium ions by niobium ions at peaks at $25^{\circ}, 33^{\circ}, 35^{\circ}, 46^{\circ}$, and $50^{\circ}$ [11].

Table I - Contents $( \pm 0.5 \%)$ of the main phases detected in the HAp-Nb sample after the refinement of XRD data.

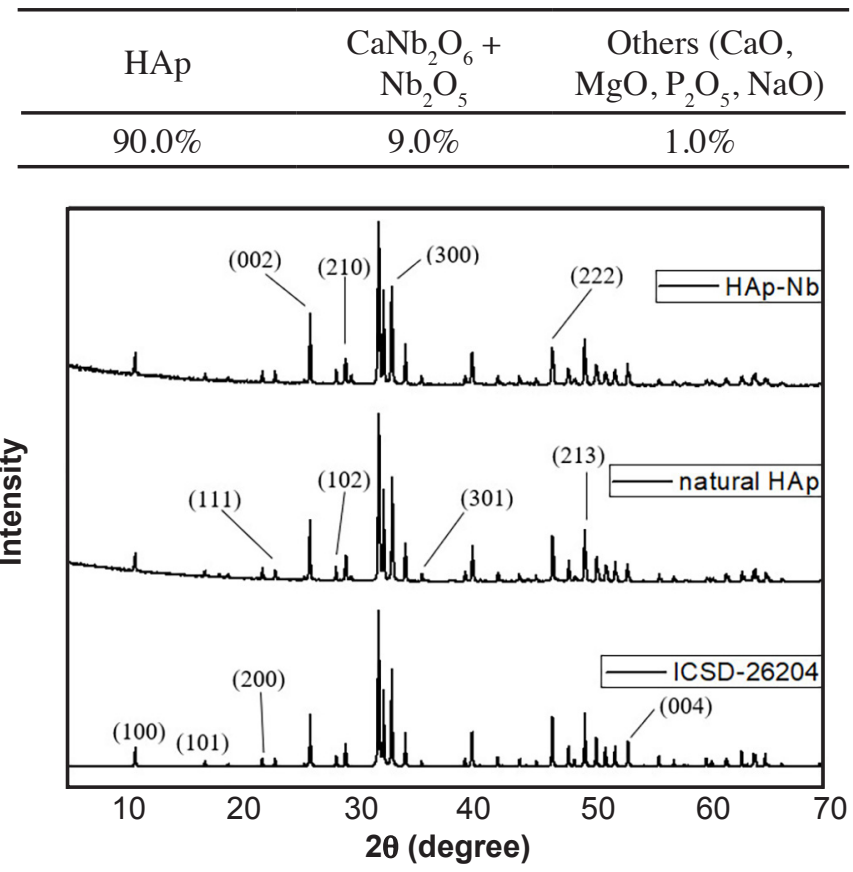

Figure 1: XRD patterns of natural HAp and hydroxyapatiteniobium samples compared to the ICSD-26204 file.

The FTIR spectroscopy confirmed XRD results. In Fig. 2, FTIR spectra show the characteristic bands of HAp due to the presence of hydroxyl, phosphate, and carbonate functional groups. The peaks in the range of 3750 to 3500 $\mathrm{cm}^{-1}$ indicated the presence of $\mathrm{OH}^{-}$and in the range of 1500 to $1250 \mathrm{~cm}^{-1}$ and at $873 \mathrm{~cm}^{-1}$ characterized the $\mathrm{CO}_{3}^{2-}$ ions. Also, the bands in the ranges of 1000 to $900 \mathrm{~cm}^{-1}$ and 610 to $560 \mathrm{~cm}^{-1}$ indicated the presence of the $\mathrm{PO}_{4}^{3-}$ ions. The peaks at 3497,631 , and $456 \mathrm{~cm}^{-1}$ confirmed the crystallinity of the powders because these wavenumbers are related to the vibrational mode of $\mathrm{OH}$ bond (hydroxyl group) [7, 18-20]. The band at $1406 \mathrm{~cm}^{-1}$ indicated the presence of the $\mathrm{CO}_{3}^{2-}$ group. Absorption in this region indicated the replacement of $\mathrm{OH}^{-}$ion (present in the chemical structure of HAp) by carbon dioxide. Also, $\mathrm{CO}_{3}{ }^{2-}$ ions confirmed the formation of HAp because this group is found in the inorganic phase of bone (biological hydroxyapatite phase) [21]. Moreover, the curve profile was maintained after the replacement of $\mathrm{Ca}^{2+}$ ions by $\mathrm{Nb}$ ions in the hydroxyapatite structure [22-24]. Besides, the spectrum of HAp-Nb did not show a significant difference compared to the natural HAp spectrum. However, in the curve of the HAp-Nb sample, the peak of the carbonate group had a lower intensity than the same group in the curve of the natural HAp sample. This could be a consequence of the phosphate groups replaced by negatively charged 
niobate species. So, the decrease in the number of phosphate groups in the structure could cause a reduction of the sites for the incorporation of carbonate groups in the main phase. Besides, the vibrational contributions of niobium oxides were not observed in the spectra of Fig. 2 due to these groups being outside the detectable range [25]. The HAp$\mathrm{Nb}$ sample showed peaks of the carbonate functional group in the region between 2500 and $2250 \mathrm{~cm}^{-1}$ because this sample was more exposed to the atmospheric air. According

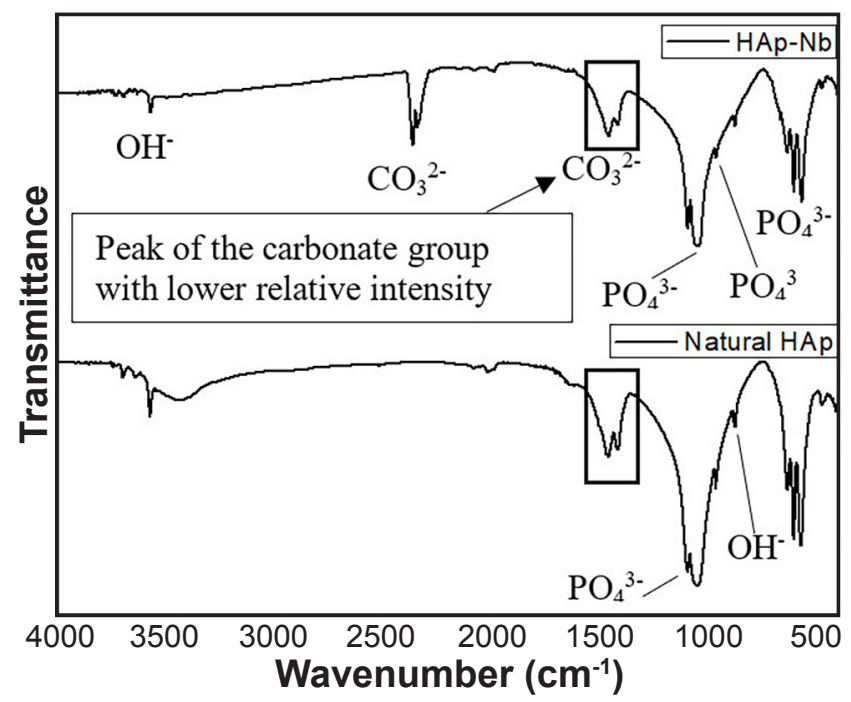

Figure 2: FTIR spectra of natural HAp and HAp-Nb samples.

Table II - FTIR spectroscopy results of the HAp-Nb sample.

\begin{tabular}{cc}
\hline Wavenumber $\left(\mathrm{cm}^{-1}\right)$ & Functional group \\
\hline$\sim 3570$ & $\mathrm{O}-\mathrm{H}$ \\
$\sim 960$ & $v_{1}\left(\mathrm{PO}_{4}^{3-}\right)$ \\
$\sim 470$ & $v_{2}\left(\mathrm{PO}_{4}^{3-}\right)$ \\
$1090-1032$ & $v_{3}\left(\mathrm{PO}_{4}^{3-}\right)$ \\
$602,563,575$ & $v_{4}\left(\mathrm{PO}_{4}^{3-}\right)$ \\
$1660,1300,873$ & $\mathrm{CO}_{3}^{2-}$ \\
\hline
\end{tabular}

Table III - XRF spectroscopy results (\%) of HAp-Nb.

\begin{tabular}{cccccc}
\hline Sample & $\mathrm{Ca}$ & $\mathrm{P}$ & $\mathrm{Nb}$ & Others & $\mathrm{Ca} / \mathrm{P}$ molar ratio \\
\hline 1 & 28.9 & 18.2 & 1.00 & 1.90 & 1.58 \\
2 & 28.7 & 18.2 & 1.44 & 1.66 & 1.58 \\
\hline
\end{tabular}

to Capanema et al. [25], the carbonate groups are detected by characterization due to the presence of surface ions. The carbonate ions replaced the sites of the $\mathrm{PO}_{4}^{3-}$ and $\mathrm{OH}^{-}$ ions. The result of this substitution was the formation of carbonated hydroxyapatite. Table II shows the results of IR spectroscopy for the detected functional groups.

Table III shows the results of X-ray fluorescence (XRF) analysis. Results confirmed the presence of the metallic $\mathrm{Nb}$ element in the sample with an average content of $\sim 1 \%$. According to Rocha et al. [17], the addition of metallic ion caused a decrease in the size of HAp crystals due to the ionic radius of niobium being smaller than of calcium. In high concentrations, niobium inhibits the growth of HAp crystals, and this would cause a delay in the growth of crystals in the apatite phase [17]. The percentage of $\mathrm{Ca}$ element had precedence in literature due to the presence of $\mathrm{CaO}$. Besides, the content of $\mathrm{Ca}$ was higher than the content of phosphorus (P) because the doping in the ceramic structure probably did not occur at the $\mathrm{PO}_{4}^{3-}$ site [17]. Moreover, the $\mathrm{Ca} / \mathrm{P}$ molar ratio found was lower than the apatite phase found in the literature $(1.58<1.67$ [4] $)$ due to the doping procedure, which decreased the amount of calcium ions in the sample, while the number of the phosphate ions remained constant. The temperature of heat treatment in the first stage of the experiment was crucial to obtain a crystalline profile of the sample. Besides, the doping with niobium ions maintained the crystalline phase due to the abundance of exchangeable sites [26]. Heat treatment time favored the atomic diffusion within the particles, and it reduced the presence of the pores. This diffusion contributed to the homogenization of the niobium ions introduced in the ceramic structure [27].

Table IV summarizes the results of the crystallite size, lattice parameters, and volume of the unit cell of the synthesized powders. The heat treatment of the samples contributed to grain growth. The HAp-Nb sample prepared with ultrasound had a smaller crystallite size compared to the HAp sample without ultrasound. This fact confirmed the XRF data because the niobium ion inhibits the growth of the HAp crystals. Besides, this result confirmed the introduction of $\mathrm{Nb}$ ions into the sites that contained calcium in the structure. The effect of the doping with $\mathrm{Nb}$ in the $\mathrm{PO}_{4}^{3-}$ sites was to the increase of lattice parameters a and c (Table IV). The chemical species with $\mathrm{Nb}(\mathrm{V})$ has an ionic radius greater than the $\mathrm{PO}_{4}^{3-}$, and there is an increase in the parameters of the samples with $\mathrm{Nb}$ [25]. The samples submitted to the ultrasound had a smaller size of crystallites, confirming the efficiency of the physical interference procedure. The

Table IV - Crystallite size, crystallinity, and lattice parameters of the synthesized powders.

\begin{tabular}{cccccc}
\hline Sample & $\begin{array}{c}\text { Crystallite size } \\
(\mathrm{nm})\end{array}$ & $\begin{array}{c}\text { Crystallinity } \\
(\%, \pm 3 \%)\end{array}$ & $\begin{array}{c}\mathrm{a}=\mathrm{b} \\
(\AA)\end{array}$ & $\begin{array}{c}\mathrm{c} \\
(\AA)\end{array}$ & $\begin{array}{c}\text { Cell volume } \\
\left(\AA^{3}\right)\end{array}$ \\
\hline HAp with ultrasound & 52.3 & 48 & 9.414 & 6.887 & 528.5 \\
HAp without ultrasound & 128.5 & 34 & - & - & - \\
HAp-Nb with ultrasound & 50.0 & 51 & 9.426 & 6.981 & 529.4 \\
HAp-Nb without ultrasound & 104.0 & 39 & - & - & - \\
\hline
\end{tabular}


effects of the physical interference were the dissolution of particles and the precipitation of chemical species. This result showed a decrease in the size of the crystallites after the physical ultrasound interference procedure. Besides, there was an increase in the unit cell volume of the HAp-Nb sample compared to the HAp sample, both prepared with ultrasonication, due to the effective replacement of niobate species in the $\mathrm{PO}_{4}^{3-}$ sites in the hydroxyapatite structure.

Fig. 3 shows the X-ray diffraction patterns of the HAp$\mathrm{Nb}$ samples prepared with and without physical ultrasound interference. The curve of the sample with physical ultrasound interference showed more isolated peaks. This could be a consequence of using a wet route and a physical interference to present a qualitative improvement in the XRD pattern. Similar results were found in other studies [28, 29], which showed the use of physical interference methods for increasing the crystallinity of the samples. In HAp samples, the crystallinity increased from $34 \%$ to $48 \%$ after the ultrasound application. Besides, HAp-Nb samples showed an increase in crystallinity from $39 \%$ to $51 \%$. The physical effects induced by the ultrasound method provided crystallites with a smaller size, and the refinement of XRD results indicated a higher crystallinity. The size of the crystallites decreased significantly after the ultrasound method. In HAp$\mathrm{Nb}$ samples, the crystallite size decreased from 104 to $50 \mathrm{~nm}$. According to Barbosa [28], the crystallites with a size of less than $100 \mathrm{~nm}$ improve the interaction in applications of the biomaterials to implants and bone restoration. The results of the refinement of the XRD data confirmed the obtention of a material with a higher crystallinity after the application of the ultrasound method. The crystallinity is an important property for bioceramic materials because it contributes to making these materials more resistant to degradation and resorption.

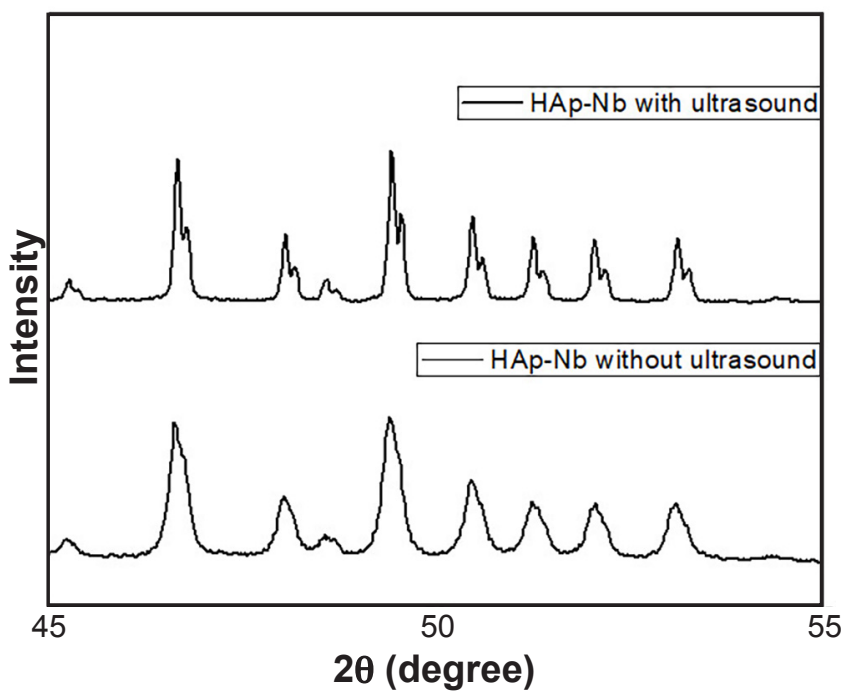

Figure 3: X-ray diffraction patterns of the HAp-Nb samples prepared with and without physical ultrasound interference.

Fig. 4 shows the results of scanning electron microscopy of the HAp-Nb samples prepared with and without physical ultrasound interference. Both samples showed the formation of polygonal grain structures and agglomerated particles. The morphology of the sample prepared with ultrasound showed smoother particles due to the ultrasound procedure to induce the dissolution and the precipitation of solids. Meanwhile, the sample prepared without ultrasound showed a higher particle density. The doping procedure and the physical ultrasound interference were important steps in the methodology to obtain a defined morphology. The samples submitted to the physical ultrasound interference presented more isolated particles due to the dispersion and intense agitation process [28]. Besides, the HAp-Nb sample prepared with ultrasound showed particles with smaller crystallites (Table IV).

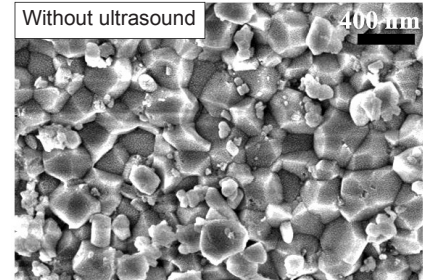

a)

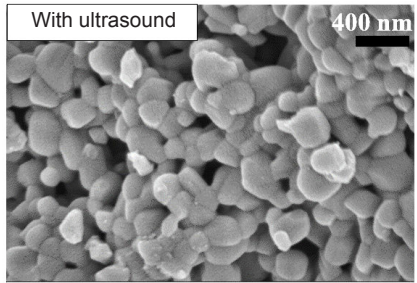

b)
Figure 4: SEM micrographs of HAp-Nb samples prepared without (a) and with (b) physical ultrasound interference.

\section{CONCLUSIONS}

This study demonstrated the efficiency of the experimental process to obtain natural hydroxyapatite from fish scales as the raw material. Furthermore, the doping with niobium ions was optimized by the physical ultrasound interference, as shown by the XRD and SEM results. The refinement of XRD results showed an increase in the crystallinity from $34 \%$ to $51 \%$ and a decrease in the size of crystallites from 128 to $50 \mathrm{~nm}$. The micrographs showed smoother and more isolated particles after the application of the physical ultrasound method. As such, the combination of the synthesis steps was efficient for the laboratory production of an $\mathrm{Nb}$-doped HAp powder, and the results indicated excellent physicochemical characteristics of the sample. Therefore, this article confirmed a new route for the production of a ceramic material doped with metallic ions for implants and bone restoration applications.

\section{ACKNOWLEDGMENTS}

The authors are grateful to the Foundation for Research Support of the State of Amazonas (FAPEAM) for financial support and the Pro-Rectory of Research and Graduate Studies (PROPESP) of the Federal University of Amazonas for the support for the realization of this research.

\section{REFERENCES}

[1] A. Moraes, A. Bierhalz, A. Pires, Quím. Nova 38, 7 (2015) 957.

[2] A. Prasad, B. Devendar, M.R. Sankar, P. Robi, Mater. 
Today Proc. 2, 4 (2015) 1216.

[3] M. Tang, N. Krishnamra, J. Thongbunchoo, N. Charoenphandhu, P. Suntornsaratoon, W. Pon-On, Mater. Sci. Eng. 62 (2015) 183.

[4] R.F. Bonan, P.R.F. Bonan, A.U.D. Batista, J.E. Oliveira, R.R. Menezes, E.S. Medeiros, Cerâmica 60, 355 (2014) 402. [5] T.S.A. Batista, J.B. Santos-Filho, Calcita, hidroxiapatita e $\beta$-fosfato tricálcio como absorvedores do ultravioleta, IFS, Aracaju (2016).

[6] S. Kongsri, K. Janpradit, K. Buapa, S. Techawongstien, S. Chanthai, Chem. Eng. J. 215-216 (2013) 522.

[7] B. Mondal, S. Mondal, A. Mondal, N. Mandal, Mater. Charact. 121 (2016) 112.

[8] A.N.K.A. Fara, H.Z. Abdullah, AIP Conf. Proc. 1669 (2015) 20077.

[9] N.N. Panda, K. Pramanik, L.B Sukla, Bioproc. Biosyst. Eng. 37, 3 (2013) 433.

[10] R.K. Brundavanam, G.E.J. Poine, D. Fawce, Am. J. Mater. Sci. 3, 4 (2013) 84.

[11] N. Demirkol, N.F. Oktar, S.E. Kayali, Eng. Mater. 529530 (2013) 29.

[12] E. Simomukay, E.C.F. de Souza, S.R.M. Antunes, C.P.F. Borges, M.D. Michel, A.C. Antunes, Cerâmica 62, 361 (2016) 9.

[13] I.L. Denry, J.A. Holloway, R.J. Nakkula, J.D. Walters, J. Biomed. Mater. Res. B 75 (2005) 18.

[14] M. Tamai, K. Isama, R. Nakaoka, T. Tsuchiya, J. Artif. Organs 10 (2007) 8.

[15] A. Obata, Y. Takahashi, T. Miyajima, K. Ueda, T. Narushima, T. Kasuga, ACS Appl. Mater. Interfaces 4, 10 (2012) 5684.

[16] P. Wei, J. Fang, L. Fang, K. Wang, X. Lu, F. Ren, Appl. Mater. Today 15 (2019) 531.
[17] D.N. Rocha, M.H.P. Silva, L.A. Gobbo, J. Mater. Res. Technol. 2, 1 (2013) 24.

[18] X. Gao, C. Dai, W. Liu, R. Shen, X. Zheng, K. Duan, J. Weng, S. Qu, J. Mater. Sci. Mater. Med. 28, 6 (2017) 83.

[19] S. Paul, A. Pal, A.R. Choudhury, S. Bodhak, V.K. Balla, A. Sinha, M. Das, Ceram. Int. 43, 17 (2017) 15678.

[20] G.A. dos Santos, A.A. Barbosa, L.M. de Oliveira, A.V. Ferraz, N.C. Olivier, W. Acchar, A.C.S. Dantas, Cerâmica 63, 368 (2017) 557.

[21] N. Muhammad, Y. Gao, F. Iqbal, P. Ahmad, R. Ge, U. Nishan, A. Rahim, G. Gonfa, Z. Ullah, Sep. Purif. Technol. 161 (2016) 129.

[22] Y. Sogo, A. Ito, K. Fukasawa, T. Sakurai, N. Ichinose, Mater. Sci. Technol. 20, 9 (2004) 1079.

[23] T.J. Webster, E.A. Massa-Schlueter, J.L. Smith, E.B. Slamovich, Biomaterials 25, 11 (2004) 2111.

[24] Y. Sogo, A. Ito, K. Senda, A. Oyane, A. Yamazaki, R.Z. Legeros, J. Biomed. Mater. Res. 1, 3 (2006) 134.

[25] N.S.V. Capanema, A.A.P. Mansur, S.M. Carvalho, A.R.P. Silva, V.S. Ciminellí, H.S. Mansur, Materials 8 (2015) 4191.

[26] M.F. Rolland, T.J. Cole, M. Sempé, J. Tichet, C. Rossignol, A. Charraud, Eur. J. Clin. Nutr. 45 (1991) 13.

[27] K.A.S. Farias, W.J.B. Sousa, M.J.B. Cardoso, R.J.S. Lima, M.A. Rodriguez, M.V.L. Fook, Cerâmica 65, 373 (2019) 99.

[28] M.C. Barbosa, "Síntese de hidroxiapatita por via úmida assistida por métodos físicos", Un. Vale Paraíba, S. José Campos (2014).

[29] A.L. Macipe, J.G. Morales, R.R. Clemente, Adv. Mater. 10 (1998) 49.

(Rec.27/10/2019, Rev.24/01/2020,31/03/2020, 22/06/2020, 14/07/2020, Ac. 19/07/2020) 